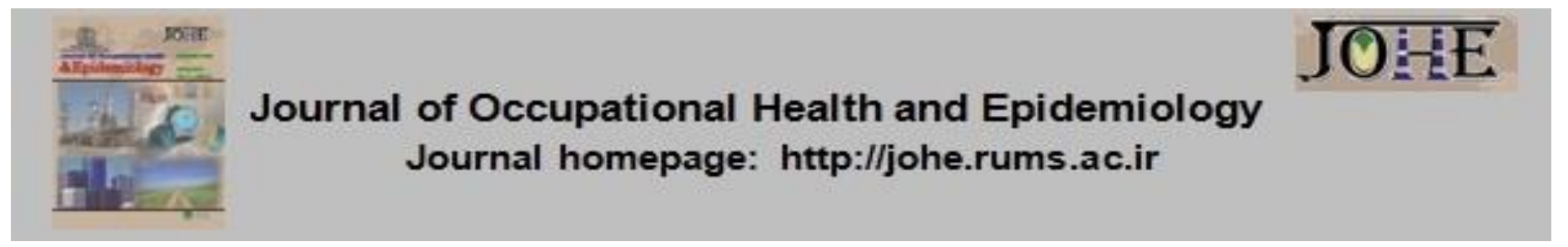

\title{
The Effect of Working-based Individual Protective Behaviors (WIPB) on COVID- 19 Mortality in North-West of Iran: A Case-Control Study
}

\author{
Telma Zahirian Moghadam¹, Farhad Pourfarzi², Chiman Karami ${ }^{3}$, Shima Rahimpouran ${ }^{1}$, Hamed \\ Zandian $^{1^{*}}$, Abdollah Dargahi ${ }^{1^{*}}$
}

1. Assistant Prof., Social Determinants of Health Research Center, Ardabil University of Medical Sciences, Ardabil, Iran.

2. Professor, Gastroenterology and Liver Disease Research Center, Ardabil University of Medical Sciences, Ardabil, Iran.

3. Assistant Prof., Dept. of Microbiology, Parasitology and Immunology, Ardabil University of Medical Sciences, Ardabil, Iran.

\section{Article Info \\ * Corresponding author: \\ Hamed Zandian, \\ Abdollah Dargahi, \\ E-mail: \\ zandian.hamed899@gmail.com, a.dargahi29@yahoo.com}

\section{Article history}

Received: Sep 2021

Accepted: Nov 2021

10.52547/johe.10.3.158

Print ISSN: 2251-8096 Online ISSN: 2252-0902

Peer review under responsibility of Journal of Occupational Health and Epidemiology
Citation: Zahirian Moghadam T, Pourfarzi F, Karami C, Rahimpouran S, Zandian H, Dargahi A. The Effect of Working-based Individual Protective Behaviours (WIPB) on COVID-19 Mortality in North-West of Iran: A Case-Control Study. J Occu Health Epidemiol 2021; 10(3):158-68. 
due to the COVID-19 disease [5]. It should be mentioned that Iran is ranked 8th in the world in terms of coronavirus infection (https://www.worldometers.info/coronavirus/). The COVID-19 outbreak will be flat in the new year in Iran if public and social behavior initiatives stick with current patterns or improve $[2,6,7]$.

Working-based Individual Protective Behaviours (WIPB) have a significant impact on the patterns of infectious disease transmission, including COVID19 , which threatens the current health system and social organization. They are protective behaviors enacted by people to protect themselves or others from a threat to their health $[8,9]$. Until vaccination is fully implemented worldwide, effective social and individual prevention is the only option to neutralize COVID-19. The modeling and interpreting social action processes (e.g., use of mask and social distance), as well as their contextualization with respect to countries' cultural systems, can lead to a stronger national and local reaction to an epidemic [10]. In addition, a retrospective analysis provided evidence of WIPB's key role in preventive actions in the control of acute respiratory syndrome (SARS) in 2003 [11]. WHO Statistical Monitoring reports that prevention and control guidelines lead to a reduction in healthcare-related infections. Various preventive options can be considered as a potential intervention to combat COVID-19 [12]. According to $\mathrm{WHO}$ guidelines, infection prevention and control is a practical and evidence-based way to avoid harm to healthy people via preventable infections [13, 14]. Coronavirus-related infections may be transmitted through contact, droplets, and airborne [1, 15]. Given the global emergency for COVID-19 infections, only WIPB remains to limit its prevalence. WIPB is a personal protective behavior and a primary prevention method such as using gloves, masks, and disinfectants, as well as washing hands against Covid 19 disease. The transmission is minimized with proper prevention.

The main basis of preventing viral infection is the regular use of soap or sanitizer and personal protective equipment (appropriate mask, eye protection, face) [16]. Also, to control COVID-19 in different countries, especially Iran, various actions have been taken. Closing school, urging people to stay home, reducing the number of close physical interactions among people are some of such actions. Social distancing has simultaneously disrupted the everyday lives of the entire population wherever it has been implemented [1719]. Such large and sudden disruptions to everyday life are likely to impact human well-being, particularly among people living in dense urban settings with limited public space. For example, elders, who are mainly at risk of suffering from lethal effects of COVID-19, are a risk group by also suffering from anxiety and depression sue to social isolation [20, 21]. All prevention actions utilized for the communicable COVID-19 disease cause loss of usual routine and reduce social and physical contact, which have frequently been reported to cause boredom, frustration, and a sense of isolation from the rest of the world, in turn resulting in distress, depression, stress, low mood, irritability, insomnia, and post-traumatic stress symptoms [22]. This frustration is exacerbated by not being able to take part in usual day-to-day activities, such as shopping for necessities [23], which is associated with harmful health outcomes [18]. In general, essential workers who provide crucial or fundamental public services, including healthcare, social care, sanitary services, and transportation, have continued attending work to carry out their daily duties. These critical worker groups have been exposed to the SARS-CoV-2 virus as a result, which may bring them into close contact with members of the public infected, especially since carriers may be infectious without, or before, exhibiting symptoms.

There are many unanswered questions about the COVID-19 epidemic, from the epidemic situation to the factors that reduce or eliminate the disease, especially regarding the impact of WIPB on the prevention and risk of COVID-19, in people's minds, particularly in high-risk locations where overcrowding is a major concern. Care in using the recommended precautions is especially important for all patients with respiratory diseases [27]. Even if they are not suspected of having COVID-19, they may be carriers; thus, regular use of these preventive and control measures in health behavior is recommended [14]. Therefore, in this study, we examine the effect of WIPB (using masks, disinfectants, gloves) on coronavirus disease (COVID-19) mortality in the northwest of Iran.

\section{Materials and Methods}

The present study is a case-control study performed on the data obtained from patients hospitalized due to coronavirus disease and the healthy population of Ardabil province, located in the northwest of Iran with a population of about 1.3 million and a gender composition of $58 \%$ men and $48 \%$ women. Fig 1 presents the map of the northwest of Iran. Data were acquired from a retrospective medical record recorded in the integrated information system of patients with COVID-19 in Ardabil province. The information of all infected patients with COVID-19 registered in the mentioned system was collected from March 
21 to September 20,2020, in the form of a census, which included a total of 1955 files. The information in this study was related to the total coronavirus data (of admitted patients) in hospitals in all cities of Ardabil province. Exclusion criteria for the case group were incorrect or incomplete patient information in the system, patients with reasons for hospitalization other than Covid-19, and patients who stated, at the time of admission, that they did not want their data to be used. The data related to the control group were extracted from the information registered in the comprehensive health care system of the province (SIB system) based on the national code and the random sampling method. Exclusion criteria for the control group were patients with incomplete information in the SIB system, unavailability of the selected person, or people who were unwilling to collaborate on the study (who was replaced with a similar person from the same system). For the case group, 1133 healthy individuals without a history of COVID-19 were selected in the relevant period.

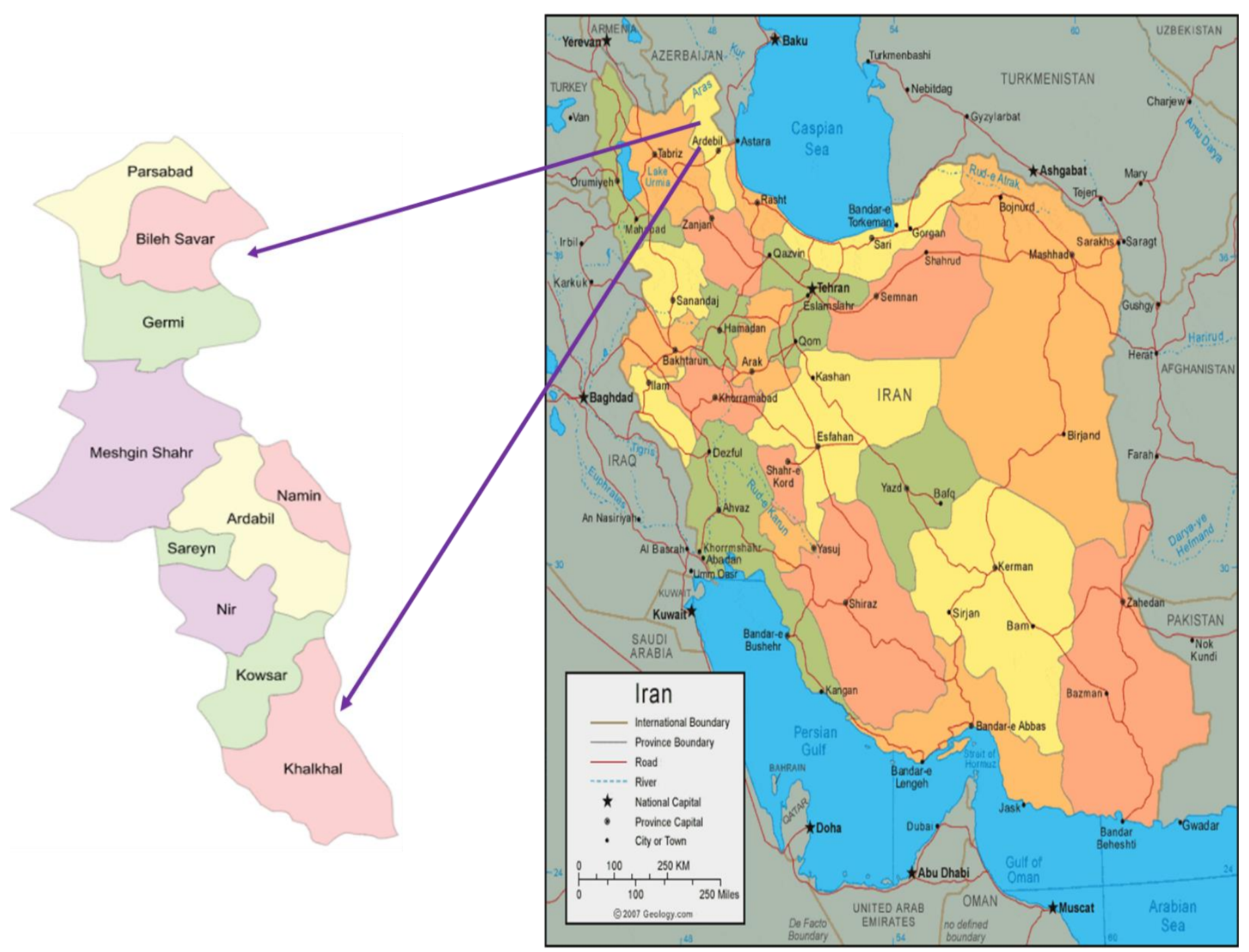

Fig. 1. Area of study (cities of Ardabil province located in northwestern Iran during the SARS-CoV-2 pandemic)

The data collection tool in the present study was a questionnaire to identify the health behaviors of patients and healthy individuals, being designed electronically and used as an information system. The validity of the tool was measured using the content validity method, and its value was equal to 0.84. In addition, in evaluating the reliability of this scale, Cronbach's alpha coefficient was obtained to be 0.79 , indicating its good reliability. The dependent variable in the present study was considered to be mortality due to COVID-19. The WIPB of the case and control groups included four sections, i.e., contact and travel history, direct contact with customers or clients, observance of health protocols at work and home, and presence in different circles and places during 14 days. The incubation period for COVID-19 disease, which is the time between exposure to the virus (becoming infected) and symptom onset, is on average 5-6 days, but it can be up to 14 days [28, 29]. For this purpose, a period of 14 days was considered. Demographic variables, including age $(<10$ to $>80$ years), gender (male and female), place of residence (provincial capital or affiliated cities), underlying disease states (diabetes, obesity, as well as cardiovascular, lung, and metabolic 
diseases), smoking (Yes/No), body mass index (from underweight to overweight), and occupational groups (direct contact with customers, Yes/No) were considered and relevant information were collected for all participants. According to the job classification plan (approved by the Islamic consultative assembly in the second socio-economic development plan of Iran and then notified to the organizations by the government), jobs in Iran can be classified into one of the eight groups presented in Table 1 [30]. In this study, we divided participants into eight occupational groups, including unemployed or housewife, educational workers, official employees, medical staff, shopkeepers, farmers/ranchers, police officers, protective service workers, social service workers, and transport workers. Unemployed and housewives were categorized as separate groups.

Table 1. Jobs in Iran classified by governmental organizations

\begin{tabular}{cl}
\hline Row & \multicolumn{1}{c}{ Description } \\
\hline $\mathbf{1}$ & The field of educational, cultural, and artistic affairs (such as teachers and professors) \\
\hline $\mathbf{2}$ & Administrative and financial field (such as bank officers and private insurances officers) \\
\hline $\mathbf{3}$ & Field of social affairs (such as all fields of research in psychology, sociology, political science, etc.) \\
\hline $\mathbf{4}$ & $\begin{array}{l}\text { The field of health and treatment (including all professions of medicine, dentistry, paramedical, nursing, } \\
\text { etc.) }\end{array}$ \\
\hline $\mathbf{5}$ & Field of services (including all brokerage, shopkeepers, sales, mechanics, etc.) \\
\hline $\mathbf{7}$ & $\begin{array}{l}\text { The field of agriculture and environment (including farming and harvesting jobs, etc.) } \\
\text { etc.) }\end{array}$ \\
\hline $\mathbf{8}$ & The field of data processing (including all occupations related to information, etc.) \\
\hline
\end{tabular}

Accurate t-test and Chi-square were used to evaluate and compare the case and control groups in terms of demographic and background variables. Also, Fisher tests were used to examine the relationship between two groups of unpaired data in the case of qualitative data availability. A Chi-square test with a significance level of 0.05 was considered to compare the two groups in terms of health behaviors. Multivariate logistic regression was used to investigate the relationship between independent and contextual background with COVID-19 mortality in inpatients.

\section{Results}

The frequency of people involved in coronavirus disease in the whole society in Ardabil province is shown in Fig 2. According to the figure, the highest and lowest society infected with coronavirus in the province were related to Ardabil and Kowsar cities, respectively. Also, the percentage of coronavirus infection, mortality, and recovery of people hospitalized were equal to $1.63 \%, 0.09 \%$, and $1.51 \%$, respectively.

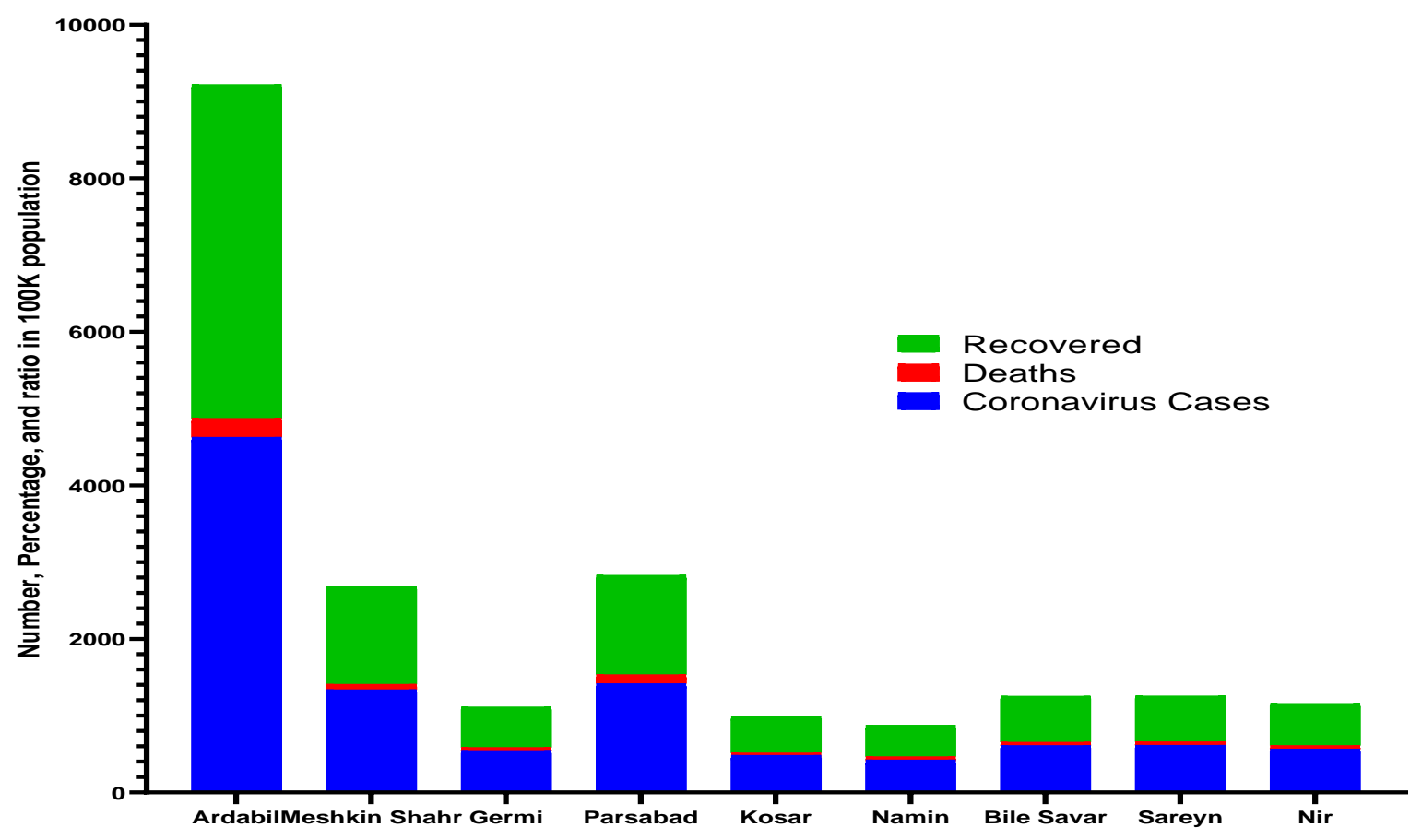

Fig. 2. The frequency distribution of whole people in Ardabil province involved in coronavirus disease 
In total, 3088 participants (1955 case and 1133 control) completed the questionnaires. Table 2 shows the sociodemographic characteristics of the study participants. The majority of the participants for the case samples had the following features: being over the age of 40 years $(81.8 \%)$, female $(53.6 \%)$, from subordinate cities $(74.6 \%)$, having cardiovascular diseases; (32.84\%), being nonsmokers (95.7\%), official employees (17.7\%) and overweight $(65.7 \%)$. According to the results, the highest occupational groups at risk of Covid-19 disease were housewives $(27.6 \%)$, official employees (18.4\%), social service workers $(15.9 \%)$, shopkeepers $(11.6 \%)$, medical staff (8.3\%), educational workers $(7.2 \%)$, farmer/rancher $(6.5 \%)$, transport workers $(2.3 \%)$, and police officers $(2.2 \%)$, respectively. Also, there was a statistically significant difference between case and control groups in terms of all studied parameters (except the place of residence and occupation), including age, sex, NonCommunicable Diseases (NCDs), smoking, and Body Mass Index (BMI) $(p<0.001)$.

Table 2. Sociodemographic characteristics of study participants $(n=3088)$

\begin{tabular}{|c|c|c|c|c|c|c|c|}
\hline & & \multicolumn{2}{|c|}{ Case $(n=1955)$} & \multicolumn{2}{|c|}{ Control $(n=1133)$} & \multicolumn{2}{|c|}{ Total } \\
\hline & & Frequency & Percent & Frequency & Percent & $\mathrm{Chi}^{2}$ & P-value \\
\hline \multirow{9}{*}{ Age categories } & $<10$ & 42 & 2.1 & 3 & 0.3 & \multirow{9}{*}{547.03} & \multirow{9}{*}{$<0.001$} \\
\hline & $10-19$ & 17 & 0.9 & 35 & 3.1 & & \\
\hline & $20-29$ & 84 & 4.3 & 122 & 10.8 & & \\
\hline & $30-39$ & 213 & 10.9 & 269 & 23.7 & & \\
\hline & $40-49$ & 261 & 13.4 & 325 & 28.7 & & \\
\hline & $50-59$ & 321 & 16.4 & 209 & 18.4 & & \\
\hline & $60-69$ & 403 & 20.6 & 127 & 11.2 & & \\
\hline & $70-79$ & 350 & 17.9 & 36 & 3.2 & & \\
\hline & $>80$ & 264 & 13.5 & 7 & 0.6 & & \\
\hline \multirow{2}{*}{ Sex } & Male & 908 & 46.4 & 616 & 54.4 & \multirow{2}{*}{18.01} & \multirow{2}{*}{$<0.001$} \\
\hline & Female & 1047 & 53.6 & 517 & 45.6 & & \\
\hline \multirow{9}{*}{ Occupation groups } & $\begin{array}{c}\text { Unemployed/ } \\
\text { Housewives }\end{array}$ & 540 & 27.6 & 287 & 25.3 & \multirow{9}{*}{21.05} & \multirow{9}{*}{0.105} \\
\hline & $\begin{array}{l}\text { Educational } \\
\text { workers }\end{array}$ & 141 & 7.2 & 78 & 6.9 & & \\
\hline & $\begin{array}{c}\text { Official } \\
\text { employee }\end{array}$ & 360 & 18.4 & 220 & 19.4 & & \\
\hline & Medical staff & 162 & 8.3 & 114 & 10.1 & & \\
\hline & Shopkeepers & 227 & 11.6 & 162 & 14.3 & & \\
\hline & $\begin{array}{l}\text { Farmer / } \\
\text { rancher }\end{array}$ & 127 & 6.5 & 52 & 4.6 & & \\
\hline & Police officers & 43 & 2.2 & 20 & 1.8 & & \\
\hline & $\begin{array}{c}\text { Social service } \\
\text { workers }\end{array}$ & 311 & 15.9 & 169 & 14.9 & & \\
\hline & $\begin{array}{c}\text { Transport } \\
\text { workers }\end{array}$ & 45 & 2.3 & 31 & 2.7 & & \\
\hline \multirow{2}{*}{ Residence } & $\begin{array}{l}\text { The capital of } \\
\text { the province }\end{array}$ & 497 & 25.4 & 377 & 33.3 & \multirow{2}{*}{7.567} & \multirow{2}{*}{0.214} \\
\hline & $\begin{array}{c}\text { Subordinate } \\
\text { cities }\end{array}$ & 1458 & 74.6 & 756 & 66.7 & & \\
\hline \multirow{5}{*}{ NCDs } & Diabetes & 406 & 20.77 & 106 & 9.36 & 96.2 & $<0.001$ \\
\hline & CVDs & 642 & 32.84 & 72 & 6.35 & 283.3 & $<0.001$ \\
\hline & Obese & 412 & 21.07 & 60 & 5.30 & 137.9 & $<0.001$ \\
\hline & $\begin{array}{c}\text { Metabolic } \\
\text { disease }\end{array}$ & 90 & 4.60 & 4 & 0.35 & 43.9 & $<0.001$ \\
\hline & Lung disease & 140 & 7.2 & 53 & 4.7 & 7.54 & 0.006 \\
\hline \multirow{2}{*}{ Smoking } & Yes & 84 & 4.3 & 115 & 10.2 & \multirow{2}{*}{40.76} & \multirow{2}{*}{$<0.001$} \\
\hline & No & 1871 & 95.7 & 1018 & 89.8 & & \\
\hline \multirow{4}{*}{ BMI categories } & Underweight & 52 & 2.7 & 34 & 3.0 & \multirow{4}{*}{141.7} & \multirow{4}{*}{$<0.001$} \\
\hline & Normal weight & 340 & 17.4 & 300 & 26.5 & & \\
\hline & Overweight & 1285 & 65.7 & 501 & 44.2 & & \\
\hline & obesity & 278 & 14.2 & 297 & 26.2 & & \\
\hline
\end{tabular}

Note: $\mathrm{n}=$ Number, NCDs $=$ Non-Communicable Diseases, $C V D s=$ Cardiovascular Diseases, $\mathrm{BMI}=$ Body Mass Index 
The results related to health behaviors and protocols in hospitalized patients with COVID-19 and healthy individuals are presented in Table 3. According to the table, $61.5 \%$ of hospitalized patients with COVID-19 in the last 14 days had contact with an unknown resource. Of the 1955 hospitalized patients with COVID-19 in the last 14 days, $66.2 \%, 35.3 \%$, and $44.1 \%$ used masks, gloves, and disinfectants, respectively. While in the control group, $66.2 \%$ of the masks, $36.5 \%$ of the gloves, and $47.1 \%$ of the disinfectants were used in the last 14 days. Moreover, $49.56 \%$ of hospitalized patients with Covid-19 had daily direct contact with customers or clients, while just $31.51 \%$ of the control group had daily direct contact with customers or clients. According to the results, $24.9 \%$ of the hospitalized patients with Covid-19 went to universities, $21.8 \%$ to public gatherings, and $10.1 \%$ to hospitals during the Covid-19 pandemic period, thus probably being infected with Covid 19 disease there.

Table 3. Working-Based Individual Protective Behaviours (WIPB) in hospitalized patients with COVID-19 and healthy people $(n=3088)$

\begin{tabular}{|c|c|c|c|c|c|c|c|}
\hline & & \multicolumn{2}{|c|}{ Case $(n=1955)$} & \multicolumn{2}{|c|}{ Control $(n=1133)$} & \multicolumn{2}{|c|}{ Total } \\
\hline & & $n$ & $\%$ & $\mathrm{n}$ & $\%$ & chi $^{2}$ & P-value \\
\hline \multirow{6}{*}{$\begin{array}{c}\text { Contact } \\
\text { with/traveling }\end{array}$} & $\begin{array}{l}\text { Traveling out of place of } \\
\text { residence }\end{array}$ & 328 & 16.8 & 63 & 5.3 & 84.03 & $<0.001$ \\
\hline & $\begin{array}{c}\text { Contact with patient before } \\
\text { illness }\end{array}$ & 261 & 13.8 & 103 & 9.1 & 45.04 & $<0.001$ \\
\hline & Traveling to polluted state & 125 & 6.4 & 33 & 2.9 & 75.49 & $<0.001$ \\
\hline & $\begin{array}{c}\text { Contact with medical } \\
\text { person }\end{array}$ & 32 & 1.6 & 2 & 0.2 & 14.04 & $<0.001$ \\
\hline & Contact with patient & 158 & 8.1 & 2 & 0.2 & 91.24 & $<0.001$ \\
\hline & $\begin{array}{c}\text { Contact with unknown } \\
\text { resource }\end{array}$ & 1202 & 61.5 & 1 & 0.1 & 1136.9 & $<0.001$ \\
\hline \multirow{3}{*}{$\begin{array}{c}\text { Used .... in Last } \\
14 \text { Days }\end{array}$} & Mask & 1193 & 62.9 & 750 & 66.2 & 8.22 & 0.004 \\
\hline & Gloves & 690 & 35.3 & 413 & 36.5 & 0.419 & 0.518 \\
\hline & Disinfectant & 862 & 44.1 & 534 & 47.1 & 2.67 & 0.102 \\
\hline \multirow{2}{*}{$\begin{array}{l}\text { Direct contact with } \\
\text { costomers or } \\
\text { clients }\end{array}$} & Yes & 986 & 49.56 & 354 & 31.51 & \multirow{2}{*}{13.26} & \multirow{2}{*}{0.003} \\
\hline & No & 969 & 50.43 & 776 & 68.49 & & \\
\hline \multirow{6}{*}{$\begin{array}{c}\text { Go to .... during } \\
\text { COVID-19 pandemic }\end{array}$} & Clinic & 114 & 5.8 & 82 & 7.2 & 2.38 & 0.122 \\
\hline & Hospital & 197 & 10.1 & 79 & 7.0 & 8.49 & 0.004 \\
\hline & Health center & 66 & 3.4 & 94 & 8.3 & 35.35 & $<0.001$ \\
\hline & University & 349 & 24.9 & 26 & 2.3 & 71.48 & $<0.001$ \\
\hline & Work place & 57 & 4.1 & 579 & 51.2 & 94.19 & $<0.001$ \\
\hline & Public gathering & 305 & 21.8 & 175 & 15.5 & 34.07 & $<0.001$ \\
\hline
\end{tabular}

The results related to the multivariable logistic regression model predicting death by population characteristic in inpatients are presented in Table 4. According to the table, in terms of age group, people over 50 years are most likely to die with COVID-19 disease. Further, the odds of death by COVID-19 in people over 80 years old is about 60 times and in people aged $70-80$ years is about 48 times higher than those under 10 years old $(p<0.001)$. The study results show that the odds of death due to Covid-19 in patients with direct contact with customers or clients based on their occupational status are about 3 times more than those without $(p<0.001)$. Also, in terms of using protective equipment such as masks, gloves, and disinfectants, the percentage of people in the case and control groups is high. However, they may develop Covid 19 disease due to improper use of protective equipment. Also, people living in subordinate cities are about 6 times more likely to die by COVID-19 than those living in the capital of the province. In addition, according to the results, the odds ratio of death with COVID-19 in smokers is 1.73 times higher than in non-smokers $(p<0.001)$. The odds of death by COVID-19 increase by increasing BMI; obese people die 1.63 times more than normal-weight people. Furthermore, old age $(59.59,95 \% \mathrm{Cl}, 5.76$ to $615.7)$, living in subordinate cities $(6.01,95 \% \mathrm{Cl}$, 4.47 to 8.07 ), having chronic diseases (4.60, 95\% $\mathrm{Cl}, 3.14$ to 6.72$)$, and high $\mathrm{BMI}(1.63,95 \% \mathrm{Cl}, 1.14$ to 2.35) significantly increase odds of death by COVID-19 in infected patients (Table 4). 
Table 4. Multivariable logistic regression model predicting death by population characteristic in inpatients $(n=1955)$

\begin{tabular}{|c|c|c|c|c|}
\hline & & Odd ratio & [95\% Conf. Interval] & P-value \\
\hline \multirow{9}{*}{ Age categories } & $<10$ & 1.00 (referent) & - & - \\
\hline & $10-19$ & 3.31 & 0.16 to 66.67 & 0.434 \\
\hline & $20-29$ & 2.60 & 0.12 to 55.00 & 0.538 \\
\hline & $30-39$ & 7.64 & 0.68 to 84.64 & 0.097 \\
\hline & $40-49$ & 11.07 & 1.04 to 117.6 & 0.046 \\
\hline & $50-59$ & 23.21 & 2.24 to 240.5 & 0.008 \\
\hline & $60-69$ & 27.95 & 2.75 to 283.3 & 0.005 \\
\hline & $70-79$ & 47.27 & 4.58 to 487.5 & $<0.001$ \\
\hline & $>80$ & 59.59 & 5.76 to 615.7 & $<0.001$ \\
\hline \multirow[b]{2}{*}{ Sex } & Male & 1.00 (referent) & - & - \\
\hline & Female & 1.25 & 0.93 to 1.68 & 0.133 \\
\hline \multirow{2}{*}{$\begin{array}{l}\text { Direct contact with } \\
\text { customers or clients }\end{array}$} & No & 1.00 (referent) & - & - \\
\hline & Yes & 3.05 & 1.40 to 8.38 & $<0.001$ \\
\hline \multirow{2}{*}{ Residence } & The capital of the province & 1.00 (referent) & - & - \\
\hline & Subordinate cities & 6.01 & 4.47 to 8.07 & $<0.001$ \\
\hline \multirow{6}{*}{ NCDs } & Chronic dis. & 4.60 & 3.14 to 6.72 & $<0.001$ \\
\hline & Diabetes & 2.50 & 1.95 to 3.21 & $<0.001$ \\
\hline & CVDs & 3.73 & 2.93 to 4.76 & $<0.001$ \\
\hline & Obese & 3.25 & 2.52 to 4.19 & $<0.001$ \\
\hline & Metabolic disease & 1.49 & 0.90 to 2.47 & 0.116 \\
\hline & Lung disease & 2.48 & 1.70 to 3.61 & $<0.001$ \\
\hline \multirow{2}{*}{ Smoking } & Yes & 1.73 & 0.94 to 3.18 & 0.075 \\
\hline & No & 1.00 (referent) & - & - \\
\hline \multirow{4}{*}{ BMI categorized } & Underweight & 0.55 & 0.24 to 1.29 & 0.173 \\
\hline & Normal weight & 1.00 (referent) & - & - \\
\hline & Overweight & 1.85 & 1.36 to 2.56 & $<0.001$ \\
\hline & obesity & 1.63 & 1.14 to 2.35 & 0.007 \\
\hline
\end{tabular}

$\mathrm{Cl}=$ Confidence Interval; $\mathrm{n}=$ Number, $\mathrm{NCD}=$ Non-Communicable Diseases, CVDs= Cardiovascular Diseases, $\mathrm{BMI}=$ Body Mass Index

Using personal protective equipment (Masks, gloves, and disinfectants) against COVID-19 between inpatients is shown in Fig 3. Based on the results, there were significant differences between alive and dead patients by COVID-19 in terms of using personal protective equipment $(p<0.001)$.

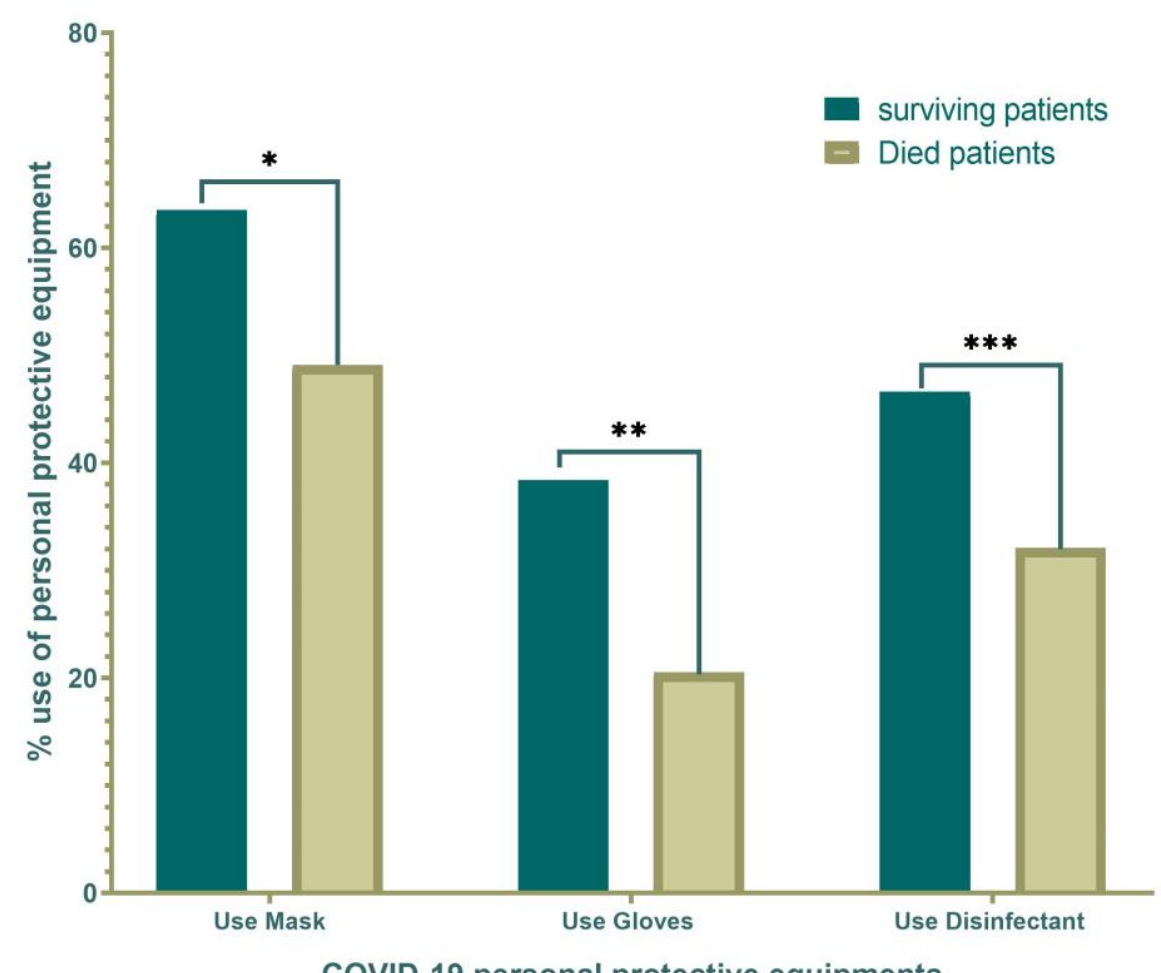

Fig. 3. Comparison of patients who died due to Covid-19 with those who survived in terms of using personal protective equipment, where there was a significant difference between the two groups in terms of * $=$ using masks $(\square 2=30.26$, $\mathrm{p}<0.001),{ }^{* *}=$ using gloves $(\square 2=36.81, \mathrm{p}<0.001)$, and ${ }^{* * *}=$ using disinfectant $(\square 2=25.26, p<0.001)$. 


\section{Discussion}

The study of Working-Based Individual Protective Behaviours (WIPB) is important in dealing with the pandemic of infectious diseases, especially in countries like Iran that are at a moderate level in terms of social behaviors [10]. The individuals' adherence to these WIPBs can be developed by providing masks, gloves, and disinfectants, as well as overwhelming the environmental barriers [31, 32]. The PPE includes gowns, goggles, gloves, face shields, and other items used by frontline health care and other essential workers. The proper use of quality-assured PPE is crucial to prevent exposure to infectious diseases, including COVID-19. This is essential to limit the acquisition and transmission of the virus to protect both health professionals and patients. Protecting health professionals not only limits disease spread, but also ensures the availability of adequate numbers of staff to cope with the inevitable increasing demands for healthcare services in the coming weeks and months ahead [33-35]. The use of personal protective equipment (PPE), especially medical masks, has become commonplace for people around the world. The present study showed that the level of adherence to WIPBs (such as the use of masks, gloves, and disinfectants) in people with COVID-19 was at a desirable level. According to the results, although the observance of hygienic behaviors such as using masks, gloves, and disinfectants in the case and control groups in the last 14 days was almost the same, many people were hospitalized for the COVID-19 virus. This was due to various reasons as follows: I) improper use of masks, gloves, and disinfectants, II) the possibility of people being present in places where a person has had COVID19 , III) the possibility of contact of gloves infected with COVID-19 virus with eyes, nose, and mouth, IV) the use of disinfectants containing a low percentage of alcohol and other disinfectants, V) the use of simple household masks with the possibility of virus penetration into it, VI) the possibility of the presence of people with masks for a long time without ventilation in places where the person has had Covid-19, VII) wrong time of mask replacement, and VIII) non-observance of social distance (at least 2m) [34, 36-41]. Social distancing prevents direct contact between people and reduces the possible transmission of viruscarrying droplets from human respiration [42]. In addition, compared to regular soaps, hand sanitizing soaps reduce the number of germs for a short period. Moreover, alcohol disinfectant limits viral growth by depositing surface proteins that break the coronavirus transmission chain [43].
In a study conducted by Sun et al. (2020) to evaluate the efficacy of social distance and ventilation in preventing COVID-19 transmission, it was detected that the increased observance of social distance by people could decrease the probability of transmission of COVID-19 disease [42].

In the study of Khazaee et al. (2020), 54.3\% of the subjects often used gloves and masks, and about $80 \%$ of the subjects used disinfectants [44, 45], which was consistent with the present study. According to the results, the probability of contacting or traveling among the people with COVID-19 was greater than the control people. In some occupations, such as taxi drivers, it can be difficult to follow health measures such as social distance. Therefore, it is very important to study the disease in such occupations [46, 47]. The results showed that in terms of jobs distribution, $540(27.6 \%)$ of people with Covid-19 disease were housewives, with the highest number in the present study. Also, the lowest number of patients were related to police officers $(2.2 \%)$ and transport workers $(2.3 \%)$, which was consistent with the study [48]. In the study of Sarailoo et al., the highest number of patients with Covid-19 disease was related to housewives. According to research, the presence of underlying diseases such as hypertension, diabetes, cardiovascular disease, chronic liver and kidney disease, cerebrovascular disease, chronic lung failure, malignancies, autoimmune diseases in the elderly (>60 years) with COVID-19 disease was greater compared to other age groups [49]. According to the results, the highest incidence of underlying diseases in people with COVID-19 was related to Cardiovascular Diseases (CVDs) (32.84\%). Moreover, the odds ratio of infecting with COVID-19 among the individuals in the age range of 50-59, 60-69, and 70-79 years, as well as the age over 80 years, were 23.21, 27.95, 42.27, and 60 times more than those in the age range of 10 years as a reference group, respectively. Various studies on the elderly with COVID-19 have shown that most of the elderly $(60.7 \%)$ have an underlying disease, and about one-third of them have two or more than two underlying diseases simultaneously [50]. Another study has shown that the fatality rate of COVID-19 disease in people over 60 years with underlying disease $(4.5 \%)$ is higher than those under 60 years (1.4\%) [51]. This could be due to the following reasons: the coronavirus located in the lungs, a change in the physical characteristics of the lung tissue, or the aging of the immune system. Normally, the lungs produce an immune response by coughing, producing mucus, and clearing the airways. These responses play an important role in 
repelling the virus out of the airways and reducing the incidence of the disease. Such responses decrease with age in the body, thus increasing the risk of developing COVID-19 in the elderly [52]. Also, the report of the Center for Disease Control and Prevention indicates that the rate of hospitalization, admission to the intensive care unit, and death due to COVID-19 at the age of over 65 years is higher than other age groups [53]; this is consistent with the present study. Moreover, according to the results, in terms of gender, the percentage of women hospitalized with COVID-19 $(53.6 \%)$ is much higher than men $(46.4 \%)$, which is consistent with the study conducted by Costa et al. (2020) [54]. In a study, Pourfarzi et al. have investigated the cause of high coronary mortality among women in Iran and Ardabil. They show that non-observance of health protocols such as wearing masks, using disinfectants, and nonobserving social distance cause high mortality and morbidity of Ardabil women [55].

The present study had some limitations, including the lack of possibility of examining the observance of social distance as one of the main health protocols. Also, in this study, the type of mask and disinfectant used by the subjects were not investigated.

\section{Conclusion}

This study showed that more than $60 \%$ of inpatients followed health protocols but were infected, possibly due to a lack of knowledge about the use of masks, gloves, and disinfectants or incomplete adherence to protocols. Older people living in subordinate cities with non-communicable diseases such as diabetes, CVDs, and obesity were identified as contributing factors to the increased mortality rate of COVID-19. Improving the observance of health protocols, including the proper use of masks, disinfectants, and gloves, as well as intensifying quarantine, can reduce the incidence and prevalence of COVID-19 disease. Given the importance of prevention, especially until the discovery and widespread use of the vaccine, it is still necessary to emphasize compliance with WIPB and protocols to prevent the spread of COVID-19.

\section{Acknowledgement}

This work was supported by the Ardabil University of Medical Sciences [grant number IR.ARUMS.REC.1399.538].

Conflict of interest: None declared.

\section{References}

1. Karami C, Dargahi A, Vosoughi $M$, Normohammadi A, Jalali F, Asghariazar V, et al. SARS-CoV-2 in municipal wastewater treatment plant, collection network and hospital wastewater. Environ Sci Pollut Res Int 2021; 1 9.

2. Zandian H, Sarailoo M, Dargahi S, Gholizadeh $H$, Dargahi A, Vosoughi M. Evaluation of knowledge and health behavior of University of Medical Sciences students about the prevention of COVID-19. Work 2021; 68(3):543-9.

3. Fauci AS, Lane HC, Redfield RR. Covid - 19 Navigating the Uncharted. N Engl J Med 2020; 382(13):1268-9.

4. Mirzaei A, Rezakhani Moghaddam H, Habibi Soola A. Identifying the predictors of turnover intention based on psychosocial factors of nurses during the COVID-19 outbreak. Nurs Open 2021; 8(6):3469-76.

5. Al-Naamani K, Al-Jahdhami I, Al-Tamtami W, Al-Amri K, Al-Khabori M, Sinani SA, et al. Prevalence and persistence of SARS-CoV2 antibodies among healthcare workers in Oman. J Infect Public Health 2021; 14(11):1578-84.

6. Zandian H, Alipouri Sakha M, Nasiri E, Zahirian Moghadam T. Nursing work intention, stress, and professionalism in response to the COVID19 outbreak in Iran: A cross-sectional study. Work 2021; 68(4):969-79.

7. Yazdi-Feyzabadi V, Alipouri Sakha M, Zandian $H$, Zahirian Moghadam T. Alcohol-related mortality during the COVID-19 outbreak in Iran: a commentary on happening a crisis amid another crisis. J Subst Use 2021; 26.doi:10.1080/14659891.2021.1961319.

8. Saito T, Asai T. Aerosol containment device for airway management of patients with COVID-19: a narrative review. J Anesth 2021; 35(3):384-9.

9. Raude J, MCColl K, Flamand C, Apostolidis T. Understanding health behaviour changes in response to outbreaks: Findings from a longitudinal study of a large epidemic of mosquito-borne disease. Soc Sci Med 2019; 230:184-93.

10. Jarynowski A, Wójta-Kempa M, Płatek D, Czopek K. Attempt to Understand Public Health Relevant Social Dimensions of COVID-19 Outbreak in Poland. 2020. Available at SSRN 3570609. doi:10.2139/ssrn.3570609 .

11. Earnshaw VA, Eaton LA, Kalichman SC, Brousseau NM, Hill EC, Fox AB. COVID-19 conspiracy beliefs, health behaviors, and policy support. Transl Behav Med 2020; 10(4):850-6.

12. Udwadia ZF, Raju RS. How to protect the protectors: 10 lessons to learn for doctors fighting the COVID-19 coronavirus. Med J Armed Forces India 2020; 76(2):128-31.

13. Güner R, Hasanoğlu I, Aktaş F. COVID-19: Prevention and control measures in community. Turk J Med Sci 2020; 50(SI-1):571-7. 
14. Sultana J, Mazzaglia G, Luxi N, Cancellieri A, Capuano A, Ferrajolo $C$, et al. Potential effects of vaccinations on the prevention of COVID-19: rationale, clinical evidence, risks, and public health considerations. Expert Rev Vaccines 2020; 19(10):919-36.

15. Vosoughi M, Karami C, Dargahi A, Jeddi $F$, Jalali KM, Hadisi $A$, et al. Investigation of SARS-CoV-2 in hospital indoor air of COVID-19 patients' ward with impinger method. Environ Sci Pollut Res Int 2021; 28(36):50480-8.

16. Pradhan D, Biswasroy $P$, Kumar Naik $P$, Ghosh G, Rath G. A Review of Current Interventions for COVID-19 Prevention. Arch Med Res 2020; 51(5):363-74.

17. Fetzer TR, Witte $M$, Hensel $L$, Jachimowicz J, Haushofer J, Ivchenko A, et al. Global Behaviors and Perceptions at the Onset of the COVID-19 Pandemic. Cambridge, United Kingdom: National Bureau of Economic Research; 2020.

18. La VP, Pham TH, Ho MT, Nguyen MH, Nguyen KLP, Vuong TT, et al. Policy Response, Social Media and Science Journalism for the Sustainability of the Public Health System Amid the COVID-19 Outbreak: The Vietnam Lessons. Sustainability 2020; 12(7):2931.

19. Azizpour I, Mehri S, Moghaddam HR, Mirzaei A, Soola $\mathrm{AH}$. The impact of psychological factors on bereavement among frontline nurses fighting Covid-19. Int J Afr Nurs Sci 2021; 15:100341.

20. Jennings V, Bamkole $O$. The Relationship between Social Cohesion and Urban Green Space: An Avenue for Health Promotion. Int J Environ Res Public Health 2019; 16(3):452.

21. Samuelsson K, Barthel S, Colding J, Macassa G, Giusti M. Urban nature as a source of resilience during social distancing amidst the coronavirus pandemic. Landscape and Urban Planning. 2020. doi: 10.31219/osf.io/3wx5a.

22. Hämmig $O$. Health risks associated with social isolation in general and in young, middle and old age. PLoS One 2019; 14(7):e0219663.

23. Brooks E, Geyer R. The development of EU health policy and the Covid-19 pandemic: trends and implications. J Eur Integr 2020; 42(8):1057-76.

24. Dean NE, Halloran ME, Yang $Y$, Longini IM. Transmissibility and Pathogenicity of Ebola Virus: A Systematic Review and Meta-Analysis of Household Secondary Attack Rate and Asymptomatic Infection. Clin Infect Dis 2016; 62(10):1277-86.

25. Baker MG, Peckham TK, Seixas NS. Estimating the burden of United States workers exposed to infection or disease: A key factor in containing risk of COVID-19 infection. PloS One 2020; 15(4):e0232452.

26. Mutambudzi M, Niedwiedz C, Macdonald EB, Leyland A, Mair F, Anderson J, et al. Occupation and risk of severe COVID-19: prospective cohort study of $120 \quad 075$ UK
Biobank participants. Occup Environ Med 2021; 78(5):307-14.

27. McIntosh K. COVID-19: Epidemiology, virology, and prevention. [Internet]. Hirsch MS, Bloom A, eds. 2020. Available from: https://www.uptodate.com/contents/covid-19epidemiology-virology-and-prevention.

28. World Health Organization. Coronavirus disease 2019 (COVID-19): Situation Report-73; Geneva, Switzerland: World Health Organization; 2020.

29. Lauer SA, Grantz KH, Bi Q, Jones FK, Zheng $Q$, Meredith HR, et al. The Incubation Period of Coronavirus Disease 2019 (COVID-19) from Publicly Reported Confirmed Cases: Estimation and Application. Ann Intern Med 2020; 172(9):577-82.

30. Islamic Consultative Assembly. Law on the Second Five-Year Economic, Social and Cultural Development Plan of the Islamic Republic of Iran. Islamic Republic of Iran: Islamic Consultative Assembly; 1994.

31. Shahnazi $H$, Ahmadi-Livani M, Pahlavanzadeh B, Rajabi A, Hamrah MS, Charkazi A. Assessing preventive health behaviors from COVID-19: a cross sectional study with health belief model in Golestan Province, Northern of Iran. Infect Dis Poverty 2020; 9(1):157.

32. Barakat AM, Kasemy ZA. Preventive health behaviours during coronavirus disease 2019 pandemic based on health belief model among Egyptians. Middle East Curr Psychiatry 2020; 27(1):43.

33. Gordon C, Thompson A. Use of personal protective equipment during the COVID-19 pandemic. Br J Nurs 2020; 29(13):748-52.

34. Dargahi A, Jeddi F, Ghobadi H, Vosoughi M, Karami $C$, Sarailoo $M$, et al. Evaluation of masks' internal and external surfaces used by health care workers and patients in coronavirus2 (SARS-CoV-2) wards. Environ Res 2021; 196:110948.

35. Summerlin-Long S, Selimos A, Brewer B, Buchanan M, Clark C, Croyle K, et al. Building a personal protective equipment monitor team as part of a comprehensive COVID-19 prevention strategy. Am J Infect Control 2021; 49(11):1443-4.

36. Setti L, Passarini F, De Gennaro $G$, Barbieri $P$, Perrone MG, Borelli $M$, et al. Airborne Transmission Route of COVID-19: Why 2 Meters/6 Feet of Inter-Personal Distance Could Not Be Enough. Int J Environ Res Public Health 2020; 17(8):2932.

37. Lüdecke $D$, von dem Knesebeck O. Protective Behavior in Course of the COVID-19 Outbreak Survey Results From Germany. Front Public Health 2020; 8:572561.

38. Zaidi STR, Hasan SS. Personal protective practices and pharmacy services delivery by community pharmacists during COVID-19 pandemic: Results from a national survey. Res Social Adm Pharm 2021; 17(1):1832-7. 
39. Storopoli J, Braga da Silva Neto WL, Mesch GS. Confidence in social institutions, perceived vulnerability and the adoption of recommended protective behaviors in Brazil during the COVID19 pandemic. Soc Sci Med J 2020; 265:113477.

40. Karami C, Normohammadi A, Dargahi A, Vosoughi $M$, Zandian $H$, Jeddi $F$, et al. Investigation of SARS-CoV-2 virus on nozzle surfaces of fuel supply stations in North West of Iran. Sci Total Environ 2021; 780:146641.

41. Dargahi A, Jeddi F, Vosoughi M, Karami C, Hadisi A, Ahamad Mokhtari S, et al. Investigation of SARS CoV-2 virus in environmental surface. Environ Res 2021; 195:110765.

42. Sun C, Zhai Z. The efficacy of social distance and ventilation effectiveness in preventing COVID-19 transmission. Sustain Cities Soc 2020; 62:102390.

43. Adams JG, Walls RM. Supporting the Health Care Workforce During the COVID-19 Global Epidemic. JAMA 2020; 323(15):1439-40.

44. Khazaee-Pool M, Shahrousvand S, Naghibi SA. Predicting Covid-19 Preventive Behaviors Based on Health Belief Model: An InternetBased Study in Mazandaran Province, Iran. J Mazandaran Univ Med Sci 2020; 30(190):56-66.

45. Kampf G, Scheithauer S, Lemmen S, Saliou P, Suchomel M. COVID-19-associated shortage of alcohol-based hand rubs, face masks, medical gloves and gowns: proposal for a risk-adapted approach to ensure patient and healthcare worker safety. J Hosp Infect 2020; 105(3):4247.

46. Pongpirul WA, Pongpirul K, Ratnarathon AC, Prasithsirikul W. Journey of a Thai Taxi Driver and Novel Coronavirus. N Engl J Med 2020; 382(11):1067-8.

47. Hu S, Wang W, Wang Y, Litvinova M, Luo K,
Ren L, et al. Author Correction: Infectivity, susceptibility, and risk factors associated with SARS-CoV-2 transmission under intensive contact tracing in Hunan, China. Nat Commun 2021; 12(1):2251.

48. Sarailoo M, Matin S, Vosoughi M, Dargahi A, Gholizadeh H, Damavandi MR, et al. Investigating the relationship between occupation and SARS-CoV2. Work 2021; 68(1):27-32.

49. Wang L, He W, Yu X, Hu D, Bao M, Liu H, et al. Coronavirus disease 2019 in elderly patients: Characteristics and prognostic factors based on 4-week follow-up. J Infect 2020; 80(6):639-45.

50. Liu K, Chen Y, Lin R, Han K. Clinical features of COVID-19 in elderly patients: A comparison with young and middle-aged patients. J Infect 2020; 80(6):e14-8.

51. Verity R, Okell LC, Dorigatti I, Winskill P, Whittaker $\mathrm{C}$, Imai $\mathrm{N}$, et al. Estimates of the severity of coronavirus disease 2019: a modelbased analysis. Lancet Infect Dis 2020; 20(6);669-77.

52. Santesmasses D, Castro JP, Zenin AA, Shindyapina AV, Gerashchenko MV, Zhang B, et al. COVID-19 is an emergent disease of aging. Aging Cell 2020; 19(10):e13230.

53. Jannat Alipoor Z, Fotokian Z. COVID-19 and the Elderly with Chronic diseases: Narrative Review. J Mil Med 2020; 22(6):632-40.

54. Costa MF. Health belief model for coronavirus infection risk determinants. Rev Saude Publica 2020; 54:47.

55. Pourfarzi F, Rahim Pouran S, Dargahi A, Karami C, Fouladi $\mathrm{N}$, Zandian $\mathrm{H}$, et al. The healthy behaviours and COVID-19 mortality among Iranian women: a case-control study. BMC Womens Health 2021; 21(1):366. 